\title{
A randomised controlled trial investigating the effect of nutritional supplementation on visual function in normal, and age-related macular disease affected eyes: design and methodology [ISRCTN78467674]
}

\author{
Hannah Bartlett* and Frank Eperjesi
}

Address: Neurosciences Research Institute, School of Life and Health Sciences, Aston University, Aston Triangle, Birmingham, B4 7ET, UK Email: Hannah Bartlett* - bartlehe@aston.ac.uk; Frank Eperjesi - F.Eperjesi@aston.ac.uk

* Corresponding author

Published: 10 October 2003

Nutrition Journal 2003, 2:12

This article is available from: http://www.nutritionj.com/content/2/I//2

(c) 2003 Bartlett and Eperjesi; licensee BioMed Central Ltd. This is an Open Access article: verbatim copying and redistribution of this article are permitted in all media for any purpose, provided this notice is preserved along with the article's original URL.
Received: 03 July 2003

Accepted: 10 October 2003

\begin{abstract}
Background: Age-related macular disease is the leading cause of blind registration in the developed world. One aetiological hypothesis involves oxidation, and the intrinsic vulnerability of the retina to damage via this process. This has prompted interest in the role of antioxidants, particularly the carotenoids lutein and zeaxanthin, in the prevention and treatment of this eye disease.

Methods: The aim of this randomised controlled trial is to determine the effect of a nutritional supplement containing lutein, vitamins $\mathrm{A}, \mathrm{C}$ and $\mathrm{E}$, zinc, and copper on measures of visual function in people with and without age-related macular disease. Outcome measures are distance and near visual acuity, contrast sensitivity, colour vision, macular visual field, glare recovery, and fundus photography. Randomisation is achieved via a random number generator, and masking achieved by third party coding of the active and placebo containers. Data collection will take place at nine and 18 months, and statistical analysis will employ Student's $\mathrm{t}$ test.

Discussion: A paucity of treatment modalities for age-related macular disease has prompted research into the development of prevention strategies. A positive effect on normals may be indicative of a role of nutritional supplementation in preventing or delaying onset of the condition. An observed benefit in the age-related macular disease group may indicate a potential role of supplementation in prevention of progression, or even a degree reversal of the visual effects caused by this condition.
\end{abstract}

\section{Background}

Epidemiology of age-related macular disease

Age-related macular degeneration is the leading cause of registrable blindness in the developed world [1-3], and its prevalence is expected to increase with the anticipated demographic right-shift [4]. In order to standardise terminology a classification system for age-related macular degeneration has been developed [5]. Early and late stages of the condition are termed age-related maculopathy (ARM) and age-related macular degeneration (AMD) respectively. The term age-related macular disease will be used to encompass ARM and AMD. 


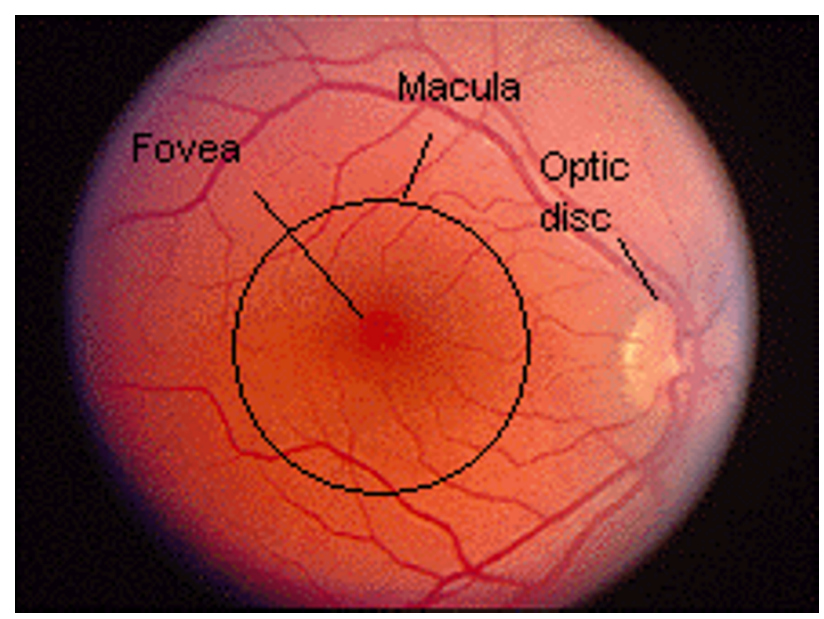

Figure I

Human fundus.

ARM is most often clinically apparent over the age of 50 years. The main symptom is increasing difficulty with fine detail discrimination. AMD is categorised further in to 'non-neovascular AMD' (also known as dry AMD or geographic atrophy), and 'neovascular AMD' (also known as wet, exudative, or disciform) [5]. Neovascular AMD refers to the growth of new, weak blood vessels and their subsequent leakage in the macular region of the retina. Nonneovascular AMD is the most common form, and is estimated to be present in $15 \%$ of eyes by 80 years of age [69]. Progression is slow and legal blindness has been estimated to occur between 5 and 10 years [10]. Neovascular AMD is less common, occurring in $5.2 \%$ of the population over 75 years [2], but accounts for $90 \%$ of blind registrations [11]. Sufferers experience rapid, significant loss of central vision. Neovascular AMD is generally preceded by the non-neovascular form.

\section{Clinicopathogenesis of age-related macular disease}

The macula is around $5 \mathrm{~mm}$ in diameter and is located centrally in the retina. It has a central depressed area, of approximately $1.5 \mathrm{~mm}$ diameter, called the fovea. The fovea is located approximately $4 \mathrm{~mm}$ temporal from the optic disc. The central floor of the fovea is called the foveola, which has a diameter of $0.35 \mathrm{~mm}$ and is the thinnest part of the retina. It contains only cone photoreceptors and their nuclei [12] (see figure 1).

\section{Aetiology of AMD}

The exact aetiology of AMD is not known, but several hypotheses have been proposed:

Age-related change to Bruch's membrane and the retinal pigment epithelium (RPE)

The RPE lies between Bruch's membrane and the sensory retina. It forms the blood-retina barrier and is involved with vitamin A metabolism, transport of metabolites from the choroid to the retina, manufacture of mucopolysaccharides, and breakdown of damaged photoreceptor outer segments. Bruch's membrane separates the RPE from the choriocapillaris, which serves as the main blood supply to the outer retina [12].

Increasing age promotes an increased lipid content of Bruch's membrane, and the macula is affected by this process to a greater extent than the periphery [13]. Consequential changes to the diffusion characteristics of Bruch's membrane may precipitate AMD [14].

Senescence of RPE cells occurs earlier than in other cell types, such as fibroblasts [15]. Foveal RPE cells decrease in density and selectively lose their hexagonal shape with age $[16,17]$. These changes may contribute to the onset of AMD.

\section{Vascular insufficiency}

Changes to the choroidal and scleral vasculature, and the resulting increase in haemodynamic resistance have been proposed to cause damage to the RPE $[18,19]$. Foveal choriocapillaris blood flow is reduced with age, but has been shown to be further degraded in AMD patients $[20,21]$. Laser Doppler flowmetry has been used to establish that choroidal blood volume is reduced via decreased density and diameter of the choriocapillaris [21].

\section{Genetics}

An increased risk of AMD has been demonstrated with a positive family history $[22,23]$, and this supports the proposed genetic component to development of AMD. It is likely that those with an inherited predisposition for the condition will develop it following exposure to certain risk factors [24].

\section{Free radicall oxidative stress hypothesis}

Reactive oxygen intermediates is an inclusive term used to describe both oxidants and free radical species [25]. A free radical can be described as 'any atom or molecule that has one or more unpaired electrons' [26]. Examples include the superoxide anion $\left(\mathrm{O}^{2-\bullet}\right)$ and the hydroxyl free radical $(\mathrm{OH} \bullet)$. Oxidants such as singlet oxygen $\left({ }^{1} \mathrm{O}_{2}\right)$ and hydrogen peroxide $\left(\mathrm{H}_{2} \mathrm{O}_{2}\right)$ contain paired electrons, but in a reactive state [27]. It is proposed that many degenerative diseases result from uncontrolled ROI reactions within the body [28]. A free radical will attempt to achieve stability by gaining electrons from other molecules. These molecules become 'reducing agents' by donating electrons and are damaged by this process. In the retina this damage may lead to the development of age-related macular disease. The retina is particularly susceptible to oxidative stress for several reasons: 
- The retina is subject to high levels of radiation, particularly blue light.

- Oxygen consumption by the retina is greater than that of other tissues [29].

- Photoreceptor outer segments contain a high proportion of polyunsaturated fatty acids, whose double bonds are a rich source of electrons [30,31].

- The retina contains photosensitisers, which make cells and tissues sensitive to the influence of irradiation [3234]

- Phagocytosis by the RPE generates ROI [35].

The body has several defence mechanisms against free radical damage, including antioxidant enzymes such as superoxide dismutase and catalase, antioxidant vitamins such as vitamins $\mathrm{C}, \mathrm{E}$ and some carotenoids, and other antioxidant compounds such as metallationein, melanin, and glutathione. For a detailed account of the role of oxidation in the pathogenesis of AMD, see Beatty et al. (2000) [36].

\section{Antioxidants and AMD}

The lack of treatment options for AMD has prompted a search for possible preventative strategies. The main risk factors for AMD are increasing age [37-41], smoking [42$44]$, and family history [22,45-47]. Proposed risk factors include female gender [2,48], white ethnicity [49-51], sunlight exposure [52,53], high dietary fat intake [54,55], hypertension [38,56-58], and low antioxidant levels $[55,59]$. It follows that the risk of developing ARM and AMD may be reduced by lifestyle changes such as cessation of smoking, minimising sunlight exposure, reducing dietary fat intake, and maintaining antioxidant levels. For a review of randomised controlled trials investigating the role of nutritional supplementation in age-related macular disease, see Bartlett and Eperjesi (2003) [60].

\section{The role of lutein and zeaxanthin in prevention and treatment of age-related macular disease}

The isometric carotenoids lutein, zeaxanthin, and mesozeaxanthin make up the macular pigment (MP) [61-63], which appears clinically as a yellow colouration to the macular area. Humans are unable to produce carotenoids but use them in a variety of functions [64]. Carotenoids are synthesised in plants, algae and bacteria [65], and the normal Western diet contains $1.3-3 \mathrm{mg} /$ day of lutein and zeaxanthin combined [66,67].

Ocular tissues contain several carotenoids, but the retina contains lutein and zeaxanthin exclusively [68]. Lutein and zeaxanthin are present in rod outer segments, where they would be most needed, and concentrations have been shown to be higher in the macular region than the peripheral retina [69]. This evidence supports the selective uptake of lutein in the retina and suggests that it plays important role in maintenance of ocular health.

A 70\% reduced risk of AMD has been demonstrated with high $(>0.67 \mu \mathrm{mol} / \mathrm{L})$ versus low $(0.25 \mu \mathrm{mol} / \mathrm{L})$ lutein/ zeaxanthin plasma levels [70]. A study of retinal levels of lutein and zeaxanthin in donor eyes found an $82 \%$ lower risk of AMD in retinae among the $25 \%$ with highest lutein and zeaxanthin levels compared to the $25 \%$ with the lowest levels [71]. Measurement of macular pigment optical density (MPOD) in healthy eyes showed an age-related decline, and healthy eyes considered to be at risk for AMD had significantly less MP than healthy eyes not at risk [72]. This evidence suggests that lower plasma and retinal levels of lutein and zeaxanthin present an increased risk of developing AMD.

Daily supplementation for 140 days with $30 \mathrm{mg}$ of lutein esters produced a seven fold increase in lutein serum levels and a $20-40 \%$ increase in MPOD [73]. A 35\% increase in lutein serum levels and a $20 \%$ increase in MPOD was demonstrated in a study supplementing 11 subjects daily with $11 \mathrm{mg}$ of lutein from $60 \mathrm{~g}$ of spinach and $150 \mathrm{~g}$ or corn/maize [74]. Supplementation with $10 \mathrm{mg} /$ day of lutein esters for 12 weeks was shown to increase serum lutein levels by five times and MPOD by approximately $20 \%$ [75]. These studies show that lutein supplementation does increase plasma and retinal lutein levels.

Lutein and zeaxanthin are believed to protect the retina in two ways. Firstly, they act as blue-light filters. Action spectrum for blue-light induced damage shows a maximum at $400 \mathrm{~nm}$ and $450 \mathrm{~nm}$, and this is consistent with the absorption spectrum of macular pigment [76]. Secondly, they are able to quench free radicals. Energy transfer to them quenches singlet oxygen, and they are also believed to react with peroxy radicals that are involved with lipid peroxidation [77].

\section{Objectives}

To determine the effect of 18 months of daily lutein and antioxidant supplementation on measures of visual function in subjects with and without age-related macular disease.

\section{Materials and Methods Recruitment}

The study requires recruitment of people with and without age-related macular disease. Recruitment methods employed include sending information to Birmingham optometrists, ophthalmologists, and a specialist centre for rehabilitation of people with sight loss, an editorial in the 
Birmingham Evening Mail, recruitment e-mails sent to the Royal National Institute for the Blind (RNIB) and all staff and students at Aston University and Aston Science Park. A project website has also been developed at http:// www.aston.ac.uk/lhs/research/nri/opo/amd. Data collection takes place in a standard consulting room at Aston University. Enrolment, randomisation, and data collection are carried out by HB. HB and FE are masked to group assignment. $\mathrm{HB}$ is a research optometrist and FE is an optometrist and lecturer at Aston University, Birmingham, UK.

\section{Inclusion/exclusion criteria}

For inclusion participants a) have to provide written informed consent, b) have to be available for three visits to Aston University, c) have to present with no ocular pathology in one eye, or no ocular pathology other than dry AMD in one eye. A cataract grading system consisting of grades one, two and three for each of cortical, nuclear, and posterior subcapsular cataracts has been developed. Participants presenting with lens opacities precluding fundus photography are excluded. Throughout the trial period, progression of any type of cataract to the successive grade will require the participant to withdraw.

Exclusion criteria include type I and II diabetes because vitamin $\mathrm{E}$ has been shown to affect glucose tolerance [7882] and diabetic retinopathy may confound the results. Those taking Warfarin medication are excluded as zinc may decrease its absorption and activity [83], as are those who use nutritional supplements that potentially raise vitamin and mineral intake above safe limits. The most recent guidelines for upper limits of nutritional supplementation are set out in the UK Food Standards Agency report [84]. Neovascular AMD and other ocular disease that could potentially interfere with the results are excluded.

\section{Masking}

The study formulation and placebo tablets have been produced by Quest Vitamins Ltd, Aston Science Park, Birmingham, B7 4AP, and are identical in external and internal appearance, and taste. The manufacturer has allocated distinguishing symbols, $\mu$ and $\lambda$. The tablets are packaged in identical, sealed, white containers; the only difference being the symbol on the label. Investigators and participants do not know which symbol represents the placebo tablets, and which represents the active formulation.

\section{Intervention}

The study formulation contains the following:

Lutein $6 \mathrm{mg}$
Vitamin A $750 \mu \mathrm{g}$

Vitamin C $250 \mathrm{mg}$

Vitamin E $34 \mathrm{mg}$

Zinc $10 \mathrm{mg}$

Copper $0.5 \mathrm{mg}$

Participants in both groups are instructed to take one tablet, at the same time every day, with food.

\section{Randomisation}

The random number generator function in Microsoft Excel is being used to allocate participants to $\mu$ and $\lambda$ groups. Odd numbers allocate to the $\mu$ group.

\section{Baseline data}

On application, participants complete a health questionnaire, a food frequency questionnaire, and a food diary. The health questionnaire provides information about general health, medication, nutritional supplementation, smoking history, ocular health, and time spent living abroad. The food questionnaire and diary ask for information about diet for analysis using Foodbase 2000 software (The Institute of Brain Chemistry and Human Nutrition, London N7 8DB).

\section{Outcome measures}

The investigation of several measures of visual function is required, as age-related macular disease can produce varying signs and symptoms.

\section{Visual acuity}

Distance and near visual acuity (VA) measured using Bailey-Lovie logMAR charts. LogMAR charts have 5 letters and $0.1 \log$ MAR progression per line. The advantage of using these charts is that they provide an equal-interval scale, and there are five letters per line. Standard Snellen charts do not provide a linear scale and have a decreasing number of letters per line as the letter size increases.

\section{Contrast sensitivity}

Contrast sensitivity (CS) is measured using a Pelli-Robson chart (Clement Clarke International, Edinburgh Way, Harlow, Essex, CM20 2TT, UK) and provides additional information about vision. The Pelli-Robson chart determines the contrast required to read large letters and is designed to test mid- to low-spatial frequencies. Some people may have normal visual acuity, but reduced contrast sensitivity at low spatial frequencies, particularly if they suffer from ocular pathologies such as age-related macular disease. 


\section{Colour vision}

Colour vision measured using the PV-16 quantitative colour vision test (Precision Vision Inc, 944 First Street, La Salle, IL, 61301, USA). Macular disease can cause a deficiency in blue-yellow colour vision as the short-wavelength photoreceptors are concentrated around the fovea.

\section{Macular Mapping Test}

Macular Mapping (MM) test (The Smith-Kettlewell Research Institute, 2318 Fillmore Street, San Francisco, CA, 94115, USA) was developed to map visual defects caused by macular disease. It was developed by MacKeben and Colenbrander [85] and differs from conventional field analysis in that the stimuli are single letters rather than spots of light. This is a novel piece of equipment and each participant is given a practice run to eliminate learning effects. At the end of the test a single figure score is presented.

\section{Glare recovery}

Eger Macular Stressometer (EMS) (Gulden Ophthalmics, Elkins Park, PA 19027) is used to assess glare recovery, also known as photostress recovery time (PSRT). This is the time taken for the regeneration of photopigments in bleached photoreceptors to a level that allows resolution of, for example, a letter at near. Resynthesis of the photopigments is dependent upon the integrity of the photoreceptors and RPE [86]; it follows that the PSRT may be extended in those with diseases affecting these structures. This is a novel piece of equipment and each participant is given a practice run to eliminate learning effects.

\section{Fundus photography}

Fundus photographs of the macular will be assessed using colour and edge analysis software.

\section{Follow up}

Data collection will take place at baseline, nine, and 18 months.

\section{Analyses}

For each outcome measure the change between baseline, nine month, and 18 month values will be calculated. A Student's t test will be used to determine whether the means of these values differ at the 5\% significance level between the placebo and active formulation results for age-related macular disease participants, and normal participants, after differences in age, gender and diet have been taken into account.

\section{Power}

From initial data collection we have calculated the treatment group sizes required in order to have $80 \%$ power at the 5\% significance level for VA, CS, MM test, and the
EMS. These values suggest that a total of 63 normal, and 96 age-related macular disease participants are required.

\section{Ethical approval}

The study has been approved by the Aston University Human Sciences Ethical Committee. The tenets of the Declaration of Helsinki are being followed [87].

\section{Discussion}

Randomised masked trials differ from observational studies in that they have the ability to demonstrate causality. The influence of confounding variables is reduced by random assignment of participants to intervention groups, and masking reduces the influence of investigator bias. There is evidence for selective deposition of lutein in the retina, increase of retinal and serum levels of lutein with supplementation, and an increased risk of age-related macular disease with reduced retinal lutein levels. This randomised controlled trial will provide further information regarding the effect of lutein and antioxidant supplementation on specific measures of visual function in people with and without age-related macular disease. The current paucity of treatment modalities for this condition has prompted research into the development of prevention strategies. A positive effect of the supplementation on normals may be indicative of its potential role in prevention or delaying the onset of age-related macular disease. This may be of particular importance for those with a positive family history, or exposure to other risk factors. A positive effect in age-related macular disease affected eyes may suggest a role of nutritional supplementation in prevention of progression of the disease, or even in reversal of symptoms.

\section{Competing interests}

None declared.

\section{Acknowledgments}

This research is funded by the College of Optometrists, UK.

\section{References}

I. Evans JR: Causes of blindness and partial sight in England and Wales 1990-I99 I. Studies on medical and population subjects Volume 57. London, HMSO; 1995.

2. Klein R, Klein BEK and Linton KLP: Prevalence of Age-Related Maculopathy - the Beaver Dam Eye Study. Ophthalmology 1992, 99:933-943.

3. Mitchell P, Smith W, Attebo K and Wang J]: Prevalence of AgeRelated Maculopathy in Australia - the Blue Mountains Eye Study. Ophthalmology 1995, I 02: |450-1460.

4. United Nations: The world population prospects: the $\mathbf{2 0 0 2}$ revision. www.un.org/esa/population/publications/wpp2000/ highlights.pdf. 2002.

5. Bird AEC, Bressler NM, Bressler SB, Chisholm IH, Coscas G, Davis MD, Dejong Ptvm, Klaver CCW, Klein BEK, Klein R, Mitchell P, Sarks JP, Sarks SH, Sourbane G, Taylor HR and Vingerling JR: An International Classification and Grading System for Age- Related Maculopathy and Age-Related Macular Degeneration. Survey of Ophthalmology 1995, 39:367-374.

6. Bressler NM, Bressler SB and Fine SL: Age-related macular degeneration. Survey of Ophthalmology 1988, 32:375-4I3. 
7. Bressler NM, Bressler SB and Fine SL: Subfoveal neovascular membranes in senile macular degeneration: relationship between membrane size and visual prognosis. Retina 1983, 3:7-II.

8. Murphy RP: Age-related macular degeneration. Ophthalmology 1986, 93:969-97|.

9. Tso MOM: Pathogenic factors of aging macular degeneration. Ophthalmology 1985, 92:628-636.

10. Arnold JJ and Sarks SH: Extracts from "Clinical evidence" - Age related macular degeneration. Br. Med. J. 2000, 32 I:74I-744.

II. Chopdar A, Chakravarthy U and Verma D: Age-related macular degeneration. British Medical Journal 2003, 326:485-488.

12. Kanski Jj: Clinical Ophthalmology. Thirdth edition. Oxford, Butterworth-Heineman; 1994.

13. Holz FG.et.al: Analysis of lipid deposits extracted from human macular and peripheral Bruch's membrane. Archives of Ophthalmology 1994, I I 2:402-406.

14. Ambati J, Ambati BK, Yoo SH, lanchulev S and Adamis AP: AgeRelated Macular Degeneration: Etiology,Pathogenesis, and Therapeutic Strategies. Survey of Ophthalmology 2003, 48:257-293.

15. Rawes V, Kipling D, Kill IR and Faragher RG: The kinetics of senescence in retinal pigment epithelial cells: a test for the telomere hypothesis of ageing? Biochemistry 1997, 62: 129|-1295.

16. Dorey CK, Wu G and Ebenstein D: Cell loss in the aging retina. Relationship to lipofuscin accumulation and macular degeneration. Invest Ophthalmol Vis Sci 1989, 30:169I-1699.

17. Watzke RC, Soldevilla JD and Trune DR: Morphometric analysis of human retinal pigment epithelium: correlation with age and location. Current Eye Research 1993, I 2:133-142.

18. Friedman E: A hemodynamic model of the pathogenesis of age-related macular degeneration. American Journal of Ophthalmology 1997, 1 24:677-682.

19. Friedman E: The role of the atherosclerotic process in the pathogenesis of age-related macular degeneration. American Journal of Ophthalmology 2000, 130:658-663.

20. Grunwald JE, Hariprasad SM and DuPont J: Effect of aging on foveolar choroidal circulation. Archives of Ophthalmology 1998, I 16:150-154.

21. Grunwald JE, Hariprasad SM and DuPont J: Foveolar choroidal blood flow in age-related macular degeneration. Investigative Ophthalmological Vision Science 1998, 39:385-390.

22. Hyman LG, Lilienfeld AM, Ferris FL and Fine SL: Senile Macular Degeneration - a Case-Control Study. Am. J. Epidemiol. 1983, I 1 8:213-227.

23. Smith $W$ and Mitchell $P$ : Family history and age-related maculopathy: the Blue Mountains Eye Study. Archives of Ophthalmology 1998, 26:203-206.

24. Bird A: Age-related macular disease. Br. J. Ophthalmol. 1996, 80:2-3.

25. Rose RC, Richer SP and Bode AM: Ocular Oxidants and Antioxidant Protection. Proceedings of the Society for Experimental Biology and Medicine 1998, 2 I 7:397-407.

26. Southorn PA and Powis G: Free radicals in medicine I. Chemical nature and biological reactions. Mayo Clinical Procedures 1988, 63:38I-389.

27. Halliwell B: Reactive oxygen species in living systems: source, biochemistry and role in human disease. Am J Med I991, 91 (Supp): 14-22.

28. Florence TM: Ther role of free radicals in disease (review). Australian and New Zealand Journal of Ophthalmology 1995, 23:3-7.

29. Sickel W: Retinal metabolism in dark and light. Handbook of sensory physiology Edited by: FuortesMGF. Berlin, Springer-Verlag; 1972:667-727.

30. Bazan NG: The metabolism of omega-3 polyunsaturated fatty acids in the eye: the possible role of docosahexaenoic acid and docosanoids in retinal physiology and ocular pathology. Progress in Clinical and Biological Research 1989, 3 I 2:95-II 2 .

31. Stone WL, Farnsworth CC and Dratz EA: A reinvestigation of the fatty acid content of bovine, rat and frog retinal rod outer segments. Experimental Eye Research 1979, 28:387-397.

32. Delmelle M: Retinal sensitized photodynamic damage to liposomes. Photochemistry and Photobiology 1978, 28:357-360.

33. Gaillard ER, Atherton SJ, Eldred $G$ and Dillon J: Photophysical studies on human retinal lipofuscin. Photochemistry and Photobiology 1995, $61: 448-453$
34. Rozanowska M, Jarvis-Evans J and Korytowski W: Blue lightinduced reactivity of retinal pigment. In vitro generation of oxygen-reactive species. Journal of Biological Chemistry 1995, 270: $18825-18830$.

35. Tate DJ Jr, Miceli MV and Newsome DA: Phagocytosis and $\mathbf{H 2 0 2}$ induce catalase and metallothionein gene expression in human retinal pigment epithelial cells. Invest Ophthalmol Vis $\mathrm{Sci}$ 1995, 36: 1271-1279.

36. Beatty S, Koh HH, Henson D and Boulton M: The role of oxidative stress in the pathogenesis of age-related macular degeneration. Surv. Ophthalmol. 2000, 45: I I5-134.

37. Kahn HA and Moorhead HB: Statistics on blindness in the Model Reporting Area 1969-1970. Washington. DC, US DHEW; 1973.

38. Goldberg J, Flowerdew G, Smith E, Brody JA and Tso MOM: Factors Associated with Age-Related Macular Degeneration - an Analysis of Data from the Ist National-Health and Nutrition Examination Survey. Am. J. Epidemiol. 1988, I 28:700-7 I0.

39. Hawkins BS, Bird A, Klein R and West SK: Epidemiology of agerelated macular degeneration. Mol. Vis. 1999, 5:U7-UIO.

40. Klein R: Epidemiology. Age-Related Macular Degeneration Edited by: Berger JW; Fine SL; Maguire MG. Philadelphia, Mosby; 1999:3I-55.

4I. Smith W, Assink J, Klein R, Mitchell P, Klaver CCW, Klein BEK, Hofman A, Jensen S, Wang JJ and de Jong Ptvm: Risk factors for age related macular degeneration - Pooled findings from three continents. Ophthalmology 200I, 108:697-704.

42. Tamakoshi, Akiko, Yuzawa, Mitsuko, Matsui and Mizuo: Smoking and neovascular form of age-related macular degeneration in late middle aged males: findings from a case-control study in Japan. British Journal of Ophthalmology 1997, 8 I:90I-904.

43. Seddon JM, Willett WC, Speizer FE and Hankinson SE: A prospective study of cigarette smoking and age-related macular degeneration in women. JAMA 1996, 276:

44. Hawkins RL: Smoking, platelets and thrombosis. Nature 1972 , 236:450-452.

45. Heiba IM,et.al: Sibling correlations and segregation analysis of age-related maculopathy: the Beaver Dam Eye Study. Genetic Epidemiology 1994, I I:5 I-67.

46. Klaver CCW, Smith and Smith: Familial aggregation of agerelated macular degeneration in the Rotterdam Study (abstract). Investigative Opthalmological Visual Science 1997, 38:S967.

47. Klaver CCW, Wolfs RCW and Assink JJM: Genetic Risk of AgeRelated Maculopathy. Population-Based Familial Aggregation Study. Archives of Ophthalmology 1998, I 16:1646-165I.

48. Kahn HA, smith and jones.: The Framingon Eye Study. I. Outline and major prevalence findings. American Journal of Epidemiology 1977, 106: 17-32.

49. Schachat AP, Hyman L, Leske MC, Connell AMS and Wu SY: Features of Age-Related Macular Degeneration in a BlackPopulation. Arch. Ophthalmol. 1995, I 1 3:728-735.

50. Friedman DS, Katz J, Bressler NM, Rahmani B and Tielsch JM: Racial differences in the prevalence of age-related macular degeneration - The Baltimore eye survey. Ophthalmology 1999, 106:1049-1055.

5I. Jampol LM and Tielsch JM: Race, Macular Degeneration, and the Macular Photocoagulation Study. Archives of Ophthalmology 1992, I 10:1699-1700

52. Cruickshanks KJ, Klein R, Klein BEK and Nondahl DM: Sunlight and the 5-year incidence of early age-related maculopathy - The Beaver Dam Eye Study. Arch. Ophthalmol. 200I, I I 9:246-250.

53. Delcourt C, Carriere I and Ponton-Sanchez A: Light Exposure and the Risk of Age-Related Macular Degeneration: The POLA Study. Archives of Ophthalmology 200 I, I I 9: | 463-1468.

54. Mares-Perlman JA.et.al: Dietary fat and age-related maculopathy. Archives of Ophthalmology 1995, I I 3:743-748.

55. Yannuzzi LA, Sorenson JA, Sobel RS, Daly JR, Derosa JT, Seddon JM, Gragoudas ES, Puliafito CA, Gelles E, Gonet R, Burton TC, Culver J, Metzger K, Kalbfleisch N, Zarling D, Farber MD, Blair N, Stelmack T, Axelrod A, Waitr SE, Cross A, Rolnick C, Flom T, Haller J, Pusin S, Cassel G, Applegate CA, Seigel D, Sperduto RD, Hiller R, Mowery R, Chew E, Tamboli A, Miller DT, Sowell AL, Gunter EW, Dunn M, Shamban K, Lento D, Alexander JA and Phillips DA: Risk-Factors for Neovascular Age-Related Macular Degeneration. Arch. Ophthalmol. 1992, I 10:1701-1708.

56. Hyman L, Smith and Smith: Risk factors for age-related maculopathy. Investigative Ophthalmological Vision Science 1992, 33:801. 
57. Smith W, Mitchell P and Leeder SR.et.al: Plasma Fibrinogen Levels, Other Cardiovascular Risk Factors, and Age-Related Maculopathy. Archives of Ophthalmology 1998, I I 6:583-587.

58. The Age-Related Eye Disease Study Research Group: Risk factors associated with age-related macular degeneration - A casecontrol study in the Age-Related Eye Disease Study: AgeRelated Eye Disease Study report number 3. Ophthalmology 2000, 1 07:2224-2232.

59. Richer S: Multicenter ophthalmic and nutritional age-related macular degeneration study part 2: antioxidant intervention and conclusions. J Am Optom Assoc 1996, 67:30-49.

60. Bartlett $\mathrm{H}$ and Eperjesi F: Age-related macular degeneration and nutritional supplementation: a review of randomised controlled trials. Ophthalmic and Physiological Optics 2003, 23:383-399.

61. Handelman GJ, Dratz EA and Reay CC: Carotenoids in the human macula and the whole retina. Invest Ophthalmol Vis Sci 1988 29:850-855.

62. Bone RA; Landrum JT; and Tarsis SL;: Preliminary identification of the human macular pigment. Vision Res 1985, 25:|53|-| 535.

63. Khachik F, Bernstein PS and Garland DL: Identification of lutein and zeaxanthin oxidation products in human and monkey retinas. Invest Ophthalmol Vis Sci 1997, 38: I802-I8II.

64. Isler O: Carotenoids. Edited by: Basel. Birkhauser-Verlag; 197I.

65. Goodwin TW: . Methods in Enzymology Volume 2 I 3. Edited by: PackerL. New York, Academic Press; 1992: I67-I72.

66. Nebeling LC, Forman MR, Graubard BI and Snyder RA: Changes in carotenoid intake in the United States. The 1987 and 1992 National Health Interview Surveys. Journal of the American Dietetic Association 1997, 97:991-996.

67. Nebeling LC, Forman MR;, Graubard BI and Snyder RA: The Impact of Lifestyle Characterisitcs on Carotenoid Intake in the United States: The 1987 National Health Interview Survey. American Journal of Public Health 1997, 87:268-27I.

68. Bernstein PS, Khachik F, Carvalho LS, Muir GJ, Zhao DY and Katz NB: Identification and quantitation of carotenoids and their metabolites in the tissues of the human eye. Experimental Eye Research 2001, 72:215-223.

69. Rapp LM, Maple SS and Choi JH: Lutein and zeaxanthin concentrations in rod outer segment membranes from perifoveal and peripheral human retina. Investigative Ophthalmology \& Visual Science 2000, 41: I200-1209.

70. EDCCS Group: Antioxidant status and neovascular agerelated macular degeneration. The Eye Disease Case Control Study Group. Archives of Ophthalmology 1993, I I I: I04- 109.

7I. Bone RA, Landrum JT, Mayne ST, Gomez CM, Tibor SE and Twaroska EE: Macular pigment in donor eyes with and without AMD: A case-control study. Invest Ophthalmol Vis Sci 200I, 42:235-240.

72. Beatty S, Murray IJ, Henson DB, Carden D, Koh $\mathrm{H}$ and Boulton ME: Macular pigment and risk for age-related macular degeneration in subjects from a Northern European population. Investigative Ophthalmology \& Visual Science 200I, 42:439-446.

73. Landrum JT, Bone RA, Joa H, Kilburn MD, Moore LL and Sprague KE: A one year study of the macular pigment: the effect of I40 days of a lutein supplement. Experimental Eye Research 1997, 65:57-62.

74. Hammond B R, Jr, Johnson EJ, Russell RM, Krinsky NI, Yeum KJ, Edwards RB and Snodderly DM: Dietary modification of human macular pigment density. Investigative Ophthalmology \& Visual Science 1997, 38:1795-1801.

75. Berendschot Ttjm, Goldbohm RA, Klopping WAA, van de Kraats J, van Norel J and van Norren D: Influence of lutein supplementation on macular pigment, assessed with two objective techniques. Invest. Ophthalmol. Vis. Sci. 2000, 41:3322-3326.

76. Ham WT Jr, Mueller HA and Ruffolo J Jr: Basic mechanisms underlying the production of photochemical lesions in the mammalian retina. Curr Eye Res 1984, 3:165-174.

77. Landrum JT and Bone RA: Lutein, zeaxanthin, and the macular pigment. Archives of Biochemistry and Biophysics 200I, 385:28-40.

78. Bierenbaum ML, Noonan FJ and Machlin LJ: The effect of supplemental vitamin $E$ on serum parameters in diabetics, post coronary and normal subjects. Nutr Rep Int 1985, 3 I: I I I I-I I80.

79. Paolisso G, D'Amore A and Giugliano D: Pharmacologic doses of vitamin $E$ improve insulin action in healthy subjects and noninsulin dependent diabetic patients. Am J Clin Nutr 1993, 57:650-656.
80. Paolisso G, D'Amore A and Galzerano D: Daily vitamin E supplements improve metabolic control but not insulin secretion in elderly type II diabetic patients. Diabetes Care 1993, 16:1433-1437.

8I. Tütüncü NB, Bayraktar $M$ and Varli K: Reversal of defective nerve condition with vitamin $E$ supplementation in type 2 diabetes. Diabetes Care 1998, 21:1915-1918.

82. Skrha J, Sindelka G, Kvasnicka J and Hilgertova J: Insulin action and fibrinolysis influenced by vitamin $E$ in obese type 2 diabetes mellitus. Diabetes Res Clin Pract 1999, 44:27-33.

83. Pinto JT: The pharmacokinetic and pharmacodynamic interactions of foods and drugs. Topics in Clinical Nutrition 1991, 6:14-33.

84. Minerals Expert Group on Vitamins and: Safe Upper Limits for Vitamins and Minerals. www.foodstandards.gov.uk/multimedia/pdfs/ vitamins2003.pdf, Food Standard Agency; 2003.

85. MacKeben $M$ and Colenbrander $A$ : The assessment of residual vision in patients with maculopathies. Non-invasive assessment of the visual system. Technical Digest 1993, 3:274-277.

86. Brindley GS: Physiology of the retina and visual pathways. Baltimore, Williams and Wilkins; 1970.

87. World Medical Association: Declaration of Helsinki. Journal of the Americal Medical Society 1997, 277:925-926.
Publish with Bio Med Central and every scientist can read your work free of charge

"BioMed Central will be the most significant development for disseminating the results of biomedical research in our lifetime. "

Sir Paul Nurse, Cancer Research UK

Your research papers will be:

- available free of charge to the entire biomedical community

- peer reviewed and published immediately upon acceptance

- cited in PubMed and archived on PubMed Central

- yours - you keep the copyright
BioMedcentral 